\title{
Influence of process parameters on single bed Ni/(AI)MCM-41 for the production of propene from ethene feedstock
}

\author{
Matthias Felischak ${ }^{1 *}$, Tanya Wolff ${ }^{2}$, Leo Alvarado Perea ${ }^{3}$, Andreas Seidel-Morgenstern $^{1,2}$, \\ Christof Hamel ${ }^{1,4}$ \\ 1 Otto von Guericke University, Institute of Process Engineering, 39106 Magdeburg, Germany; \\ 2 Max Planck Institute for Dynamics of Complex Technical Systems, 39106 Magdeburg, Germany; \\ ${ }^{3}$ Universidad Autónoma de Zacatecas, 98000 Zacatecas, México; \\ ${ }^{4}$ Anhalt University of Applied Sciences, 06366 Köthen, Germany. \\ *matthias.felischak@ovgu.de
}

ABSTRACT: A Ni aluminized mesoporous MCM-41 catalyst was prepared and applied for the direct conversion of ethene to propene. Suitable ethene conversion and good selectivity for the desired molecule propene were achieved. The catalyst placed in a packed tubular reactor was stable for more than 2000 hours with time on stream. A reaction network analysis was performed evaluating the product spectrum observed covering a large range of operating conditions. Thereby, temperature and feed concentration can be considered as significant influence parameters on the product distribution. Based on the product spectra, a modified reaction network including a catalytic cycle is suggested, which adds cracking of long-chain olefins to the conventionally considered dimerization/oligomerization and isomerization steps. Following previous publications, the catalyst presented strong deactivation behavior. It was observed that the regeneration conditions (oxygen concentration and regeneration time) are crucial parameters concerning long-time stability. Finally, a cycling reactor operation of deactivation-regeneration steps is suggested.

KEYWORDS: catalytic cycle, ethene, propene, nickel catalysts, AIMCM-41, reaction kinetics

\section{Introduction}

Over the last decades, propene became one of the central building blocks for the petrochemical industry [1]. This is mainly due to its use for the production of polypropylene and propene oxide. The growing demand cannot be satisfied with the current production technologies [1]. Therefore, new, flexible and innovative technologies are required. The dehydrogenation of propane [2], the catalytic cracking of butenes [3-5] and the metathesis of ethene and butene $[3,6]$, as well as the direct conversion of ethene to propene (ETP) $[7,8]$, are intensively investigated.

Dehydrogenation processes present very selective chemistry involving a catalytic abstraction of hydrogen from propane to give propene. One of its drawbacks is the high reaction temperature 
required $\left(>600^{\circ} \mathrm{C}\right)$ based on the chemical limitations and, thus, the occurrence of enhanced side reactions [9]. Above $700^{\circ} \mathrm{C}$, cracking to ethene and methane is strongly pronounced [10]. Various process technologies are available, which vary in terms of reactor design, reaction conditions and catalyst [5].

The catalytic cracking of longer chain olefins is an alternative route to provide propene. These olefins have to be provided by other processes. The cracking reactions proceed in complex reaction networks [11]. These include multiple undesired side reactions, such as aromatization, oligomerization and hydrogen transfer. As a result, this leads to a wide spectrum of products [12] and a subsequent separation problem as well. Zeolites like ZSM-5, ZSM-23, and MCM-22 have shown high conversion of butenes in the classical catalytic cracking temperatures range between 600 and $650^{\circ} \mathrm{C}[5,13-16]$. Modification of the zeolite ZSM-5 with potassium showed a decrease in the conversion of 1-butene [4].

With the metathesis, a fundamental organic reaction is available for the production of propene. Typical metathesis catalyzing metals are tungsten, molybdenum and rhenium. Rhenium supported on alumina oxide is applied in the Meta-4 process, [3], in which ethene and 2-butene react at $35^{\circ} \mathrm{C}$ and 60 bar in the liquid phase. It selectively produces propene at a conversion of around $60 \%$. However, due to the sensitivity of the rhenium to catalyst poison, highly purified feedstock is required. Another major application is the Olefin Conversion Technology (OCT) developed by Lummus. Tungsten supported on silica dioxide is used in a fixed bed at temperatures above $260^{\circ} \mathrm{C}$ and pressures between 30 and 35 bar. The process converts $60 \%$ of the butene and offers a propene selectivity of up to $90 \%$ [3].

All the above-mentioned technologies are characterized by major drawbacks, regarding the reaction conditions or the need for valuable feedstock. Ethene is easily obtained by conventional steam cracking. It is produced independently and constantly. Therefore, the direct conversion of available and cheap ethene to propene (ETP) is considered as very attractive. Significant research was dedicated to developing suitable catalytic systems. Taoufik et al., have reported the direct transformation of ethene into propene over a tungsten hydride supported on alumina [17]. The conversion was only $10 \%$ after $10 \mathrm{~h}$ on stream. Oikawa et al. [18] and Lin et al. [19] presented silicaaluminophosphate microporous molecular sieves, like SAPO-34 and H-ZSM-5 zeolite, as highly active catalysts for the ETP-reaction, but also faced severe deactivation with time on stream. Iwamoto et al. $[8,20]$ investigated nickel doped MCM-41 and found it to be active for the ETP reaction. Lehmann et al. [21,22] and Alvarado Perea et al. [7] studied the characteristics of $\mathrm{Ni} / \mathrm{MCM}-41$ and $\mathrm{Ni} /(\mathrm{Al}) \mathrm{MCM}-41$. 
Experimental results with ethene as the feedstock present a wide range of possible results for the conversion of the reactant and the selectivity to the desired product propene. Depending on the aluminum doping, Alvarado-Perea [7] achieved sales in the range of 0 to $85 \%$, with propene selectivity falling from just under $60 \%$ to around $40 \%$ with increasing sales. Amin [23] investigated ZSM- 5 and dealuminized variations of this catalyst. A conversion of about $20 \%$ could be achieved with varying selectivity between 5 and $30 \%$, depending on the aluminum content. However, the main products of the reaction were $\mathrm{C} 5-\mathrm{C} 10$ components. Using a $\mathrm{Ni} / \mathrm{AISBA}-15+\mathrm{MoO}_{3}-\mathrm{SiO}_{2} \mathrm{Andrei}$ [24] achieved $40 \%$ conversion and an initial selectivity of $70 \%$, which drops to $46 \%$ in $5 \mathrm{~h}$.

Dai [25] used a variety of different catalysts, including H-beta, SAPO-34 and H-SSZ-13. In this order, conversion increased from $9.1 \%$ to $61.4 \%$ and $82.9 \%$, with selectivity achieving $43.4 \%$, $68.3 \%$ and $59.5 \%$ respectively. In comparison, Oikawa [18] realized only $7.9 \%$ sales to SAPO-34 and a significant selectivity of $79.5 \%$. Ding [26], Lin [19] and Liu [27] used H-ZSM-5 with strongly varying results. Ding received $40 \%$ conversion and $30 \%$ selectivity, whereby the main products were methane and ethane. In contrast, Lin achieved $58 \%$ and $42 \%$ for turnover and selectivity. Liu added hydrogen at a reaction temperature of $675^{\circ} \mathrm{C}$ and achieved a conversion of $12 \%$ and $65 \%$ propene selectivity.

Frey [28] used Ni/MCM-48 with constant values of $68 \%$ sales and $50 \%$ propene selectivity. Another form of MCM was used by Henkel [29], Iwamoto [8,20] and, Lehmann [21]. All studies showed that conversion decreases significantly over time and that selectivity increases analogously. For all investigations a turnover of approx. $40 \%$ and a propene selectivity of $45 \%$ were achieved. $\mathrm{Li}[30]$ combined $\mathrm{NiSO}_{4}$ with rhenium oxide to gamma- $\mathrm{Al}_{2} \mathrm{O}_{3}$ by $59 \%$ in ethene and $49 \%$ in propene selectivity. Lavrenov [1,31] followed a similar approach, but with $\mathrm{PdO}$ and $\mathrm{Re}_{2} \mathrm{O}_{7}$ on $\mathrm{ZrO}_{2}$. At a temperature of $80^{\circ} \mathrm{C}, 86 \%$ conversion and $65.4 \%$ propene could be obtained.

The widely accepted mechanism as proposed by Iwamoto et al. [8] and extended for this present work, consists of three reaction steps. First, a dimerization reaction of ethene to 1-butene (eq. 1) on the nickel ion of the catalyst, followed by an isomerization of 1-butene to cis-/trans-butene (eq. 2) catalyzed by the acidic sites. Finally, a metathesis step of the generated 2-butene and unconverted ethene to provide two moles of propene (eq. 3).

$$
\begin{array}{ll}
2 \mathrm{C}_{2} \mathrm{H}_{4} \rightarrow 1-\mathrm{C}_{4} \mathrm{H}_{8} & 1 \\
1-\mathrm{C}_{4} \mathrm{H}_{8} \leftrightarrow 2-\mathrm{C}_{4} \mathrm{H}_{8} & 2 \\
\mathrm{C}_{2} \mathrm{H}_{4}+2-\mathrm{C}_{4} \mathrm{H}_{8} \rightarrow 2 \mathrm{C}_{3} \mathrm{H}_{6} & 3
\end{array}
$$


It is supposedly assumed that Nickel initiates the metathesis step [7,22]. The postulated network does not take into account the formation of relevant byproducts and their influence on the course of the reactions and a more detailed reaction network is desirable. To design and optimize the reaction system quantitative description of the underlying reaction mechanisms and kinetics is of large interest. For the investigation an aluminized MCM- 41 with a Si/Al ratio of 60 and incorporated nickel was chosen. This catalytic system has been tested with varying structural ratios and amounts of nickel [7]. The composition used here proved to be optimal in terms of catalytic activity and selectivity to the desired product, propene. The conducted experiments are chosen to obtain information about the ongoing processes. Based on the findings the reaction mechanism is verified based on the conversion of the ethene feed and the selectivity of the main reaction products. Additionally, the stability of the catalytic system is validated.

\section{Preparation of the support and catalyst}

The (AI)MCM-41 support was prepared by the method recently described by Alvarado-Perea et al. [32]. The precursor mixture had a molar composition of $1 \mathrm{SiO}_{2}: 0.35 \mathrm{CTABr}: 0.31 \mathrm{TBAOH}$ : $0.000-0.2 \mathrm{NaAlO}_{2}: 55 \mathrm{H}_{2} \mathrm{O}$ and was manually stirred for $15 \mathrm{~min}$. Sodium aluminate (NaAlO2:Al2O3 $50-56 \%$ and $\mathrm{Na} 2 \mathrm{O} 40-45 \%$ ) was used as the aluminum source, with its amount being adjusted for generating a Si/Al ratio of 60 . Subsequently, the mixture was filled into a Teflon bottle and aged $48 \mathrm{~h}$ at $100^{\circ} \mathrm{C}$ in an oven. The resulting white solid was recovered by vacuum filtration and washed with deionized water. The produced powder was dried and calcinated, as reported by AlvaradoPerea et al. [7], to carry out the corresponding characterization. The Ni/(Al)MCM-41 catalyst was prepared using the template ion exchange method [7]. Nickel nitrate (Merck, Ni2 (NO3)2.6H2O $\geq$ $99.0 \%$ ) was used as Ni precursor. The resulting mixture was thermally treated in a Teflon bottle in a muffle furnace. The light green solid was subsequently recovered through vacuum filtration, washing and drying. The final product was calcinated at $600^{\circ} \mathrm{C}$ for $6 \mathrm{~h}$ in air. The characterization of Ni/(AI)MCM-41 using XRD, N2-Physiosorption, TEM, AAS, TPR, TPO, Si CP-MAS NMR and Al MAS NMR was reported in $[7,33]$.

\section{Experimental Procedures \\ 3.1. Testing of the catalyst}

The evaluation of the catalytic activity was carried out in a fixed-bed laboratory reactor equipped with an oven (high-temperature kinetic reactor HTKR), controlled using a thermos element in the middle of the catalyst bed. The applied quartz tube had an inner diameter of $0.6 \mathrm{~cm}$. All 
experiments were performed at atmospheric pressure, with a sample mass of $0.5 \mathrm{~g}$ of catalyst, corresponding to bed length of $11.8 \mathrm{~cm}$.

The feed consisted of ethene (Linde 99.9\%) and nitrogen (Linde 99.9993\%). Different sets of experiments were performed. The following conditions were varied during the experimental study: the space velocity (weight of catalyst/flowrate, W/F) in the range of $250-2000 \mathrm{~kg}_{\mathrm{Kat}} \cdot \mathrm{s} / \mathrm{m}^{3}$ and the molar fraction of ethene in the feed between 2.5 and $25 \%$. The entity of the numerous performed steady state experiments, corresponding to different operating conditions, adds up to 120 runs with the use of a single catalytic bed. To quantify the corresponding dependence, the temperature was varied between 50 and $350^{\circ} \mathrm{C}$ in increments of $25^{\circ} \mathrm{C}$.

To investigate the catalyst bed over a longer period it was operated for 24 hours varying the temperature stepwise at constant W/F and feed ratio. To set the initial temperature, the catalyst was heated under nitrogen to the desired reaction temperature. When this temperature was reached, the inlet flow was adjusted according to the desired reaction conditions. The analysis of the composition of the reactant inlet stream and the reaction products was carried out using gas chromatography (Agilent 6890 GC/TCD with a 5973 MSD) equipped with a 30m HP-Plot Q column (Agilent Technologies).

After each experimental run, the catalyst bed was regenerated to retrieve the catalysts initial activity. For this, the fixed bed was heated to $500^{\circ} \mathrm{C}$ under nitrogen flow. When the desired temperature was reached, compressed air was added to the feed stream and the conditions were kept constant for three hours. After the catalyst oxidation, the reactor was cooled under nitrogen down to $50^{\circ} \mathrm{C}$. The catalyst showed a consistent activity and properties in subsequently carried reference runs with good reproducibility. The full set of experiments performed consisted of 120 runs. However, not all experimental runs are presented, rather a representative series of reaction conditions. 


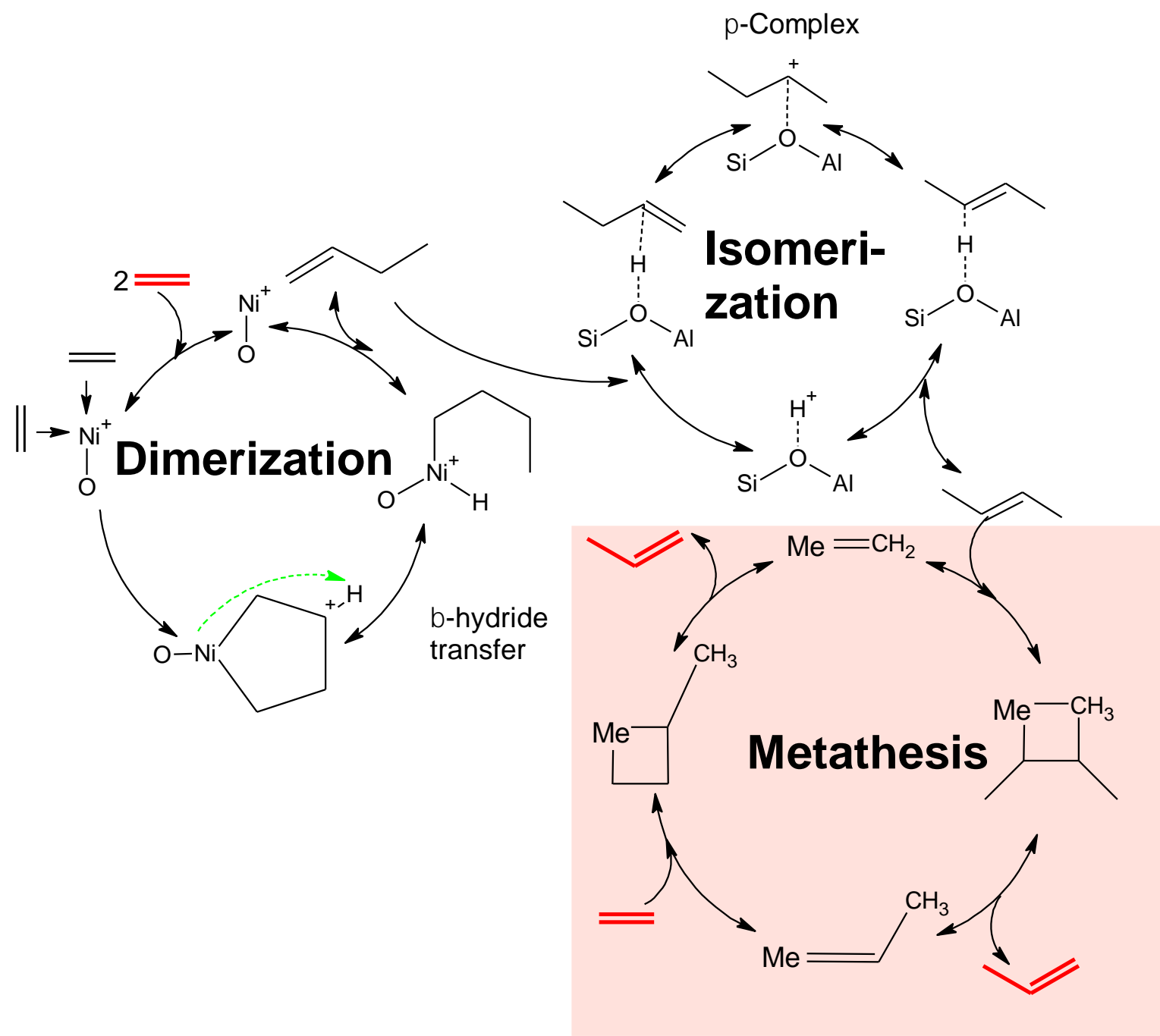

Figure 1: Mechanism of the ethene to propene (ETP) reaction based on the assumed reaction steps by Iwamoto [8].

\subsection{Data analysis}

To evaluate the performance of the catalyst the conversion of ethene, selectivity and yield for the 7 products involved $(i=1, \ldots, L)$ were calculated, namely propene, ethane, 1-butene, cis-butene, trans-butene, pentene and hexene. Iso-butene was not taken into account, because it was not detected with sufficient confidence during the experiments carried out. Additionally, the isomers of pentene and hexene were lumped into a $\mathrm{C}_{5} \mathrm{H}_{10}$ and $\mathrm{C}_{6} \mathrm{H}_{12}$ components, because the identification of the single isomers was not possible, by the analysis used.

Thus, the outputs, defined by eqs. 4-6, were evaluated. 
Conversion of ethene

$$
\mathrm{X}_{\mathrm{C}_{2} \mathrm{H}_{4}}=\frac{\dot{\mathrm{n}}_{\mathrm{C}_{2} \mathrm{H}_{4}}^{0}{ }^{-\dot{\mathrm{n}}_{\mathrm{C}_{2} \mathrm{H}_{4}}^{e x}}}{\dot{\mathrm{n}}_{\mathrm{C}_{2} \mathrm{H}_{4}}^{0}}
$$

Selectivity of component i

$$
\mathrm{S}_{\mathrm{i}}=\frac{\dot{\mathrm{n}}_{\mathrm{i}}^{e x}}{\sum_{\mathrm{k}=1}^{\mathrm{L}=7} \dot{\mathrm{n}}_{k}} \quad i=1, \ldots, L=7
$$

Yield of component $\mathrm{i}$

$$
\mathrm{Y}_{\mathrm{i}}=\frac{\dot{\mathrm{n}}_{\mathrm{i}}^{e x}}{\dot{\mathrm{n}}_{\mathrm{C}_{2} \mathrm{H}_{4}}^{0}} \cdot \frac{{ }^{\left(-\mathrm{H}_{2} \mathrm{H}_{4}\right.}{ }{ }^{2}}{v_{\mathrm{i}}} \quad i=1, \ldots, L=7
$$

Within the equations, $\dot{n}$ denotes the molar flow of a component and $v$ the stochiometric coefficient of a specific component $i$. The index 0 is related to the initial quantity. Furthermore, ex stands for the experimentally obtained value of molar current.

\section{Results}

\subsection{Influence of feed concentration and W/F}

Figure 2 shows the results of experiments for ethene feed concentration of 2.5, 5 and $10 \%$, and weight-to-flow ratios (W/F), of 250,500 and $750 \mathrm{~kg}_{\mathrm{Kat}} \cdot \mathrm{s} / \mathrm{m}^{3}$. Several trends can be identified in the graphs. With increasing reactant concentration and decreasing flow rate the conversion of ethene increases (Figure 2a). For the largest feed concentration (10 mole-\% ethene) and residence time $\left(\mathrm{W} / \mathrm{F}=750 \mathrm{~kg}_{\mathrm{Kat}} \cdot \mathrm{s} / \mathrm{m}^{3}\right.$ ) the highest conversion was obtained at $350^{\circ} \mathrm{C}$ (roughly $20 \%$ ). In the temperature range of $150-250^{\circ} \mathrm{C}$ the change in ethene slightly increases at a rather constant rate. For further increased temperatures, the ethene conversion steeply increased (except for the case of the $2.5 \%$ ethene feed). 

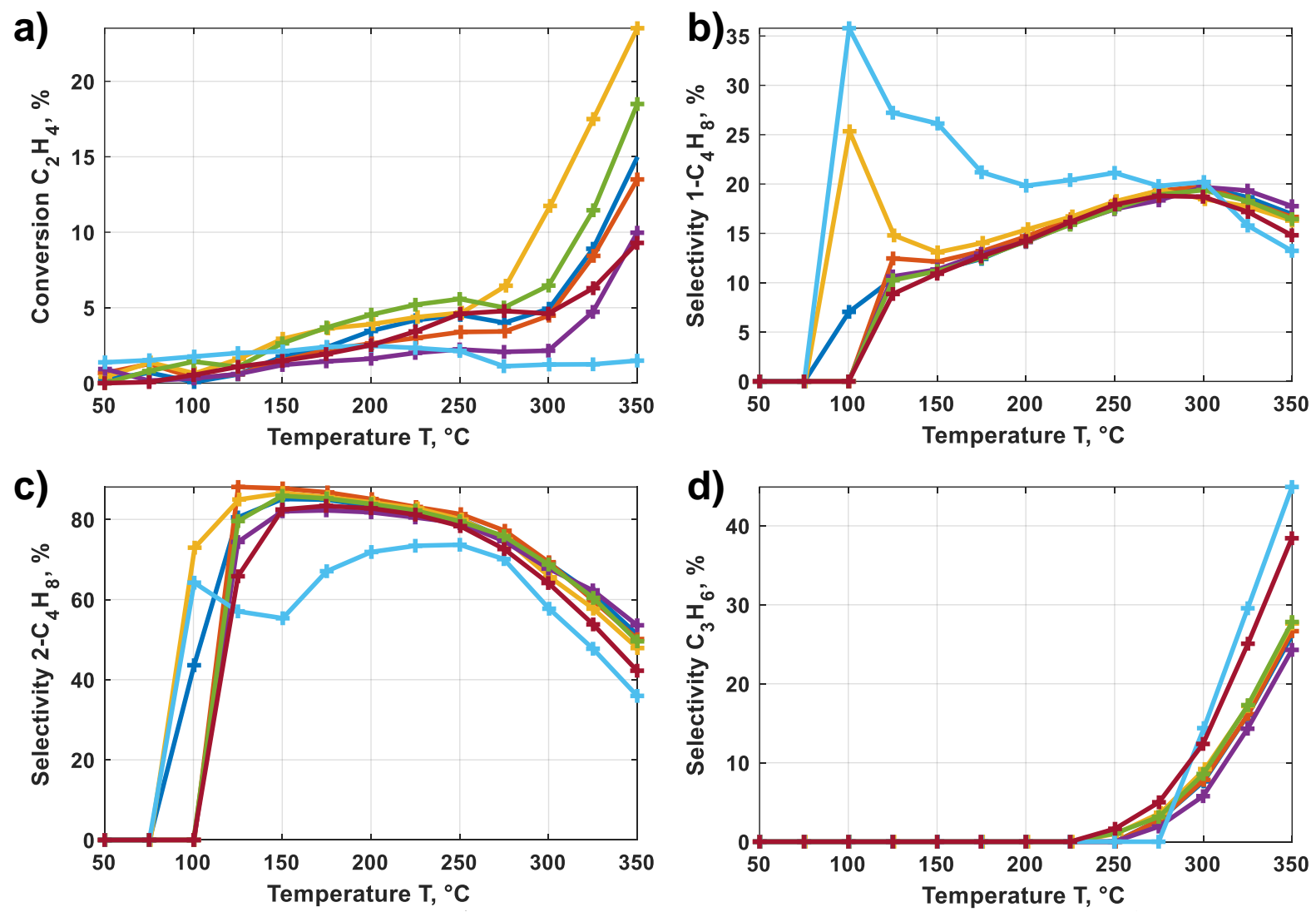

$$
\begin{aligned}
& \longrightarrow x\left(\mathrm{C}_{2} \mathrm{H}_{4}^{0}\right)=10 \mathrm{Vol}-\% ; \mathrm{W} / \mathrm{F}=500 \mathrm{~kg}_{\mathrm{Kat}} \cdot \mathrm{s} / \mathrm{m}^{3} \\
& -x\left(\mathrm{C}_{2} \mathrm{H}_{4}^{0}\right)=10 \mathrm{Vol}-\% ; \mathrm{W} / \mathrm{F}=500 \mathrm{~kg}_{\mathrm{Kat}} \cdot \mathrm{s} / \mathrm{m}^{3} \\
& \because x\left(\mathrm{C}_{2} \mathrm{H}_{4}^{0}\right)=10 \mathrm{Vol}-\% ; \mathrm{W} / \mathrm{F}=750 \mathrm{~kg} \mathrm{Kat} \cdot \mathrm{s} / \mathrm{m}^{3} \\
& \because x\left(\mathrm{C}_{2} \mathrm{H}_{4}^{0}\right)=2.5 \mathrm{Vol}-\% ; \mathrm{W} / \mathrm{F}=500 \mathrm{~kg}_{\mathrm{Kat}} \cdot \mathrm{s} / \mathrm{m}^{3} \\
& \because x\left(C_{2} H_{4}^{0}\right)=10 \mathrm{Vol}-\% ; W / F=500 \mathrm{~kg}_{\mathrm{Kat}} \cdot \mathrm{s} / \mathrm{m}^{3} \text { pre } \\
& \longrightarrow x\left(\mathrm{C}_{2} \mathrm{H}_{4}^{0}\right)=5 \mathrm{Vol}-\% ; W / F=500 \mathrm{~kg}_{\mathrm{Kat}} \cdot \mathrm{s} / \mathrm{m}^{3} \\
& \longrightarrow x\left(\mathrm{C}_{2} \mathrm{H}_{4}^{0}\right)=10 \mathrm{Vol}-\% ; \mathrm{W} / \mathrm{F}=250 \mathrm{~kg}_{\mathrm{Kat}} \cdot \mathrm{s} / \mathrm{m}^{3}
\end{aligned}
$$

Figure 2: Conversion of ethene (a), selectivity of 1-butene (b), 2-butene (c) and propene (d) over temperature for $\mathrm{Ni} /(\mathrm{Al}) \mathrm{MCM}-41(\mathrm{Si} / \mathrm{Al}=60)$.

Both, the 1- and 2-butene are produced already at temperatures around $100^{\circ} \mathrm{C}$. Therefore, the initiation of the dimerization and the faster proceeding isomerization [34] are pronounced over the entire temperature range. The catalyst is highly selective towards 2 -butenes, consisting of the cisand trans-isomer, as the main reaction product. The decreasing 2 -butene selectivity at $250^{\circ} \mathrm{C}$ corresponds to the steep increase in ethene conversion and the generation of propene. Based on similar observations Iwamoto [8] proposed metathesis to be the key reaction at higher reaction temperatures (see Figure 1). However, no typical metathesis catalyst is applied in neither his nor the present work.

Table 1 : Highest selectivity and yield data detected of the investigated temperature, feed concentration and W/F ranges covered. 


\begin{tabular}{|c|c|c|c|c|c|c|}
\hline & $\begin{array}{l}\text { Desired } \\
\text { Product }\end{array}$ & \multicolumn{2}{|c|}{ intermediates } & \multicolumn{3}{|c|}{ Undesired side products } \\
\hline & Propene & 1-Butene & 2-Butene & Pentene & Hexene & Ethane \\
\hline $\begin{array}{l}\text { Selectivity, } \\
\% \text { eq. } 5\end{array}$ & 44.9 & 35.8 & 88.1 & 4.1 & 3.4 & 3.7 \\
\hline $\begin{array}{l}\text { Temp, } \\
\text { C Feed }\end{array}$ & $\begin{array}{l}350^{\circ} \mathrm{C} \\
2.5 \%\end{array}$ & $\begin{array}{l}100^{\circ} \mathrm{C} \\
2.5 \%\end{array}$ & $\begin{array}{l}125^{\circ} \mathrm{C} \\
10 \%\end{array}$ & $\begin{array}{l}350^{\circ} \mathrm{C} \\
10 \%\end{array}$ & $\begin{array}{l}350^{\circ} \mathrm{C} \\
10 \%\end{array}$ & $\begin{array}{l}300^{\circ} \mathrm{C}, \\
10 \%\end{array}$ \\
\hline $\begin{array}{l}\text { Yield, \% } \\
\text { eq. } 6\end{array}$ & 4.6 & 3.6 & 10.7 & 1.0 & 1.0 & 0.2 \\
\hline $\begin{array}{l}\text { Temp, } \\
\text { C Feed }\end{array}$ & $\begin{array}{l}350^{\circ} \mathrm{C} \\
10 \%\end{array}$ & $\begin{array}{l}350^{\circ} \mathrm{C} \\
10 \%\end{array}$ & $\begin{array}{l}350^{\circ} \mathrm{C} \\
10 \%\end{array}$ & $\begin{array}{l}350^{\circ} \mathrm{C} \\
10 \%\end{array}$ & $\begin{array}{l}350^{\circ} \mathrm{C} \\
10 \%\end{array}$ & $\begin{array}{l}350^{\circ} \mathrm{C} \\
10 \%\end{array}$ \\
\hline
\end{tabular}

A different trend can be seen for the selectivity for the desired product propene (Figure 2d). The highest selectivity (44.9\%) was observed for the lowest feed concentration. The propene selectivity decreases with an increasing mole fraction of ethene indicating the occurrence of side reactions, e.g. enhanced oligomerization. No dependence on the selectivity on the W/F ratio was observed for the conditions considered. It was essentially influenced only by the reactant fraction in the feed stream.

The results further reveal that the route toward the C3-olefin is kinetically hindered up to $250^{\circ} \mathrm{C}$. At higher temperatures, certain pathways seem to be more pronounced leading to the desired product. The maxima of selectivity and yield observed in the entire range of the reaction conditions covered in this study are visualized in Figure 2 and summarized in Table 1. Additional information regarding the observed yields of the main reaction products is available in the supporting information (S) Figure S1.

A clear maximum of propene selectivity has not been reached for the operating temperature considered. Preliminary investigations revealed deficits of the $\mathrm{Ni} /(\mathrm{Al}) \mathrm{MCM}-41$ catalyst concerning the occurrence of severe deactivation, observed at temperatures required to achieve higher 
propene yields, namely $\mathrm{T}=450^{\circ} \mathrm{C}$ [35]. After performing experiments at these temperatures, due to the irreversible blocking of active sites by coke and possibly sintering, the catalyst could not be regenerated. The blocking is probable due to possible oligo- and aromatization of the compounds involved. Thus, to maintain sufficient catalysts activity, the reaction temperature has to be limited to approximately $300-350^{\circ} \mathrm{C}$. Therefore, the experiments were carried out up to $350^{\circ} \mathrm{C}$. This causes the limited ethene conversions and propene yields found.

\subsection{Revision of assumed reaction cycle}

From the product analysis and the obtained experimental perceptions, the mentioned reaction steps by Iwamoto and shown as a catalytic cycle in Figure 1 were found to be not sufficient to account for all phenomena observed. Formation of larger olefins, as pentenes and hexenes, can be explained by metathesis of the intermediates and oligomerization of ethene, following a pseudo-Wittig mechanism [36]. However, the appearance of saturated hydrocarbons, like ethane, and the generation of coke species cannot be explained sufficiently [37]. Based on an alternative extended reaction mechanism illustrated in Figure 3 an extended set of reaction equations is given below. According to the literature [38-42], nickel active sites catalyze the oligomerization of ethene. The main product of this step are butenes. This mechanism proceeds via oxidative coupling of ethene [43,44]. However, ethene could be further oligomerized to hexene. In addition, the butenes may dimerize as well and the coupling of ethene with butenes can occur, respectively resulting in longer chain olefins, e.g. hexene or octane. These molecules can isomerize to the thermodynamically favored internal olefins, via m-allylic carbanion using acidic sites of the catalyst [45]. The mechanism proposed here involves a conjunct polymerization up to hexene $[35,46]$ and the subsequent cracking [11,47-49]. The wide range of possible molecules can interact with the acidic sites, creating a complex network of cracking reactions. The described pathway explains the product spectrum observed in our investigations and the reaction towards propene.

The postulated cracking reaction proceeds via monomolecular protolytic cracking by $\beta$-scission of the longer chain olefins, as shown in Figure 3. Further oligomerization, aromatization and deprotonation may occur as side reactions. This is an explanation for the generation of alkanes and the severe deactivation, due to the production of coke and the following blocking of active sites. Thus, a reaction network including catalytic cracking of formed 3-hexene is suggested, which pre-dominantly results in our desired product propene. To reduce the complexity all isomers of pentene and hexene were lumped together as $\mathrm{C}_{5} \mathrm{H}_{10}$ and $\mathrm{C}_{6} \mathrm{H}_{12}$. 
Based on the proposed mechanistic cycles a more accurate derivation of reaction rates is possible. Therefore, the basis for mechanistic, kinetic models is achieved. Possibly accounting for more of the occurring effects.

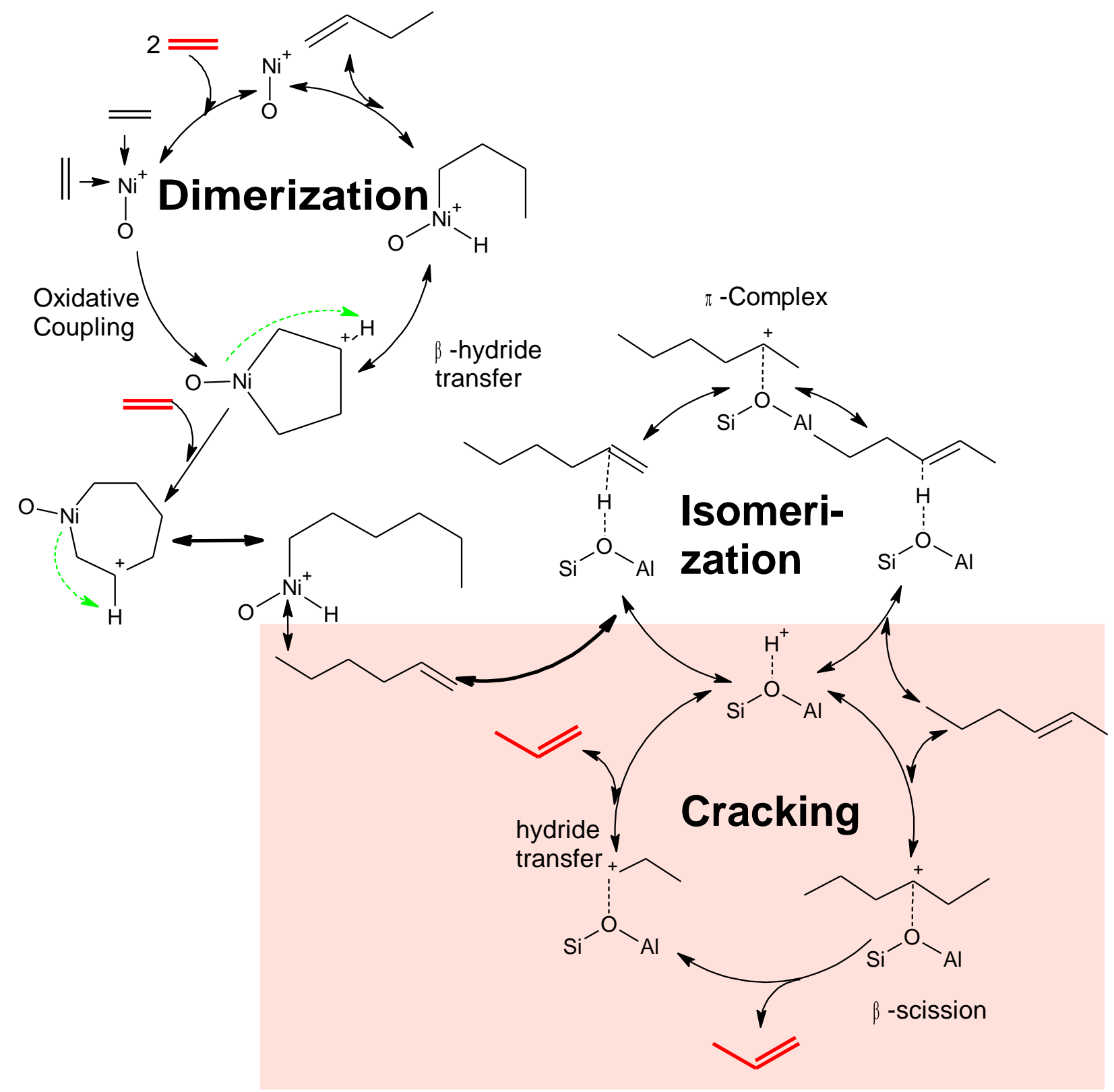

Figure 3: Proposed catalytic mechanism for the propene production from ethene, modifying the mechanism based on the proposal by Iwamoto (Figure 1), considering oligomerization and cracking steps

\subsection{Stability of the catalytic system}


From the previous investigations, a severe deactivation was observed with time on stream $[7,35]$. For the base case of $10 \%$ ethene feed and a weight-to-flow ratio of $500 \mathrm{~kg}_{\mathrm{Kat}} \cdot \mathrm{s} / \mathrm{m}^{3}$ an experiment lasting 24h was performed using the HTKR. The change in conversion and yield (Figure 4a), as well as selectivity of the measured products (Figure 4b), are pronounced and illustrated below.
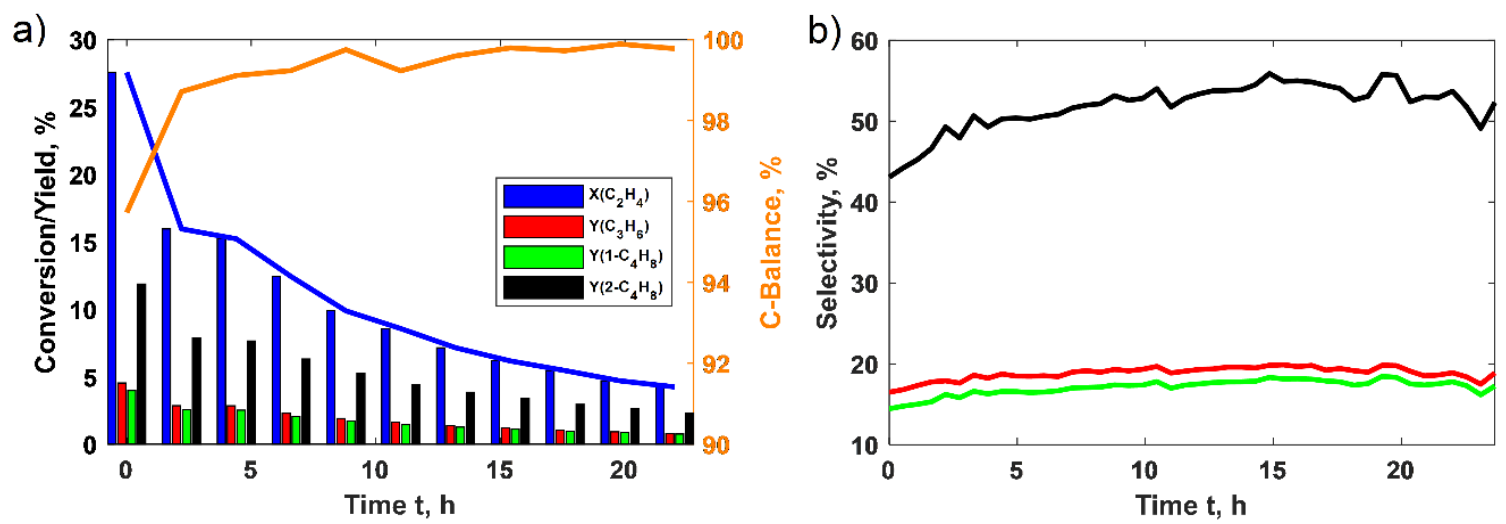

Figure 4:a) Time-dependent values of conversion and yield of the observed products with time on stream and the change in the C-Balance. b) Selectivity of the observable products as a function of time on stream for a reaction of $10 \%$ ethene feed at $350^{\circ} \mathrm{C}$, with a $W / F=500 \mathrm{~kg} K a t \cdot \mathrm{s} / \mathrm{m}^{3}$.

The graphs show that with time on stream the conversion of ethene decreases severely from $28 \%$ to values below $5 \%$. Also, the yields of the products decrease. However, the selectivity is kept constant for the entire reaction time. This indicates that the active catalytic sites are inhibited, mainly by coke like residues, but the characteristics of those sites are not changed. Therefore, under the chosen reaction conditions a simple blocking of the catalyst seems to be ongoing, without any poisoning, discharge or sintering.

The catalyst provided reproducible results for more than $2000 \mathrm{~h}$ of total reaction time with continuous regeneration. However, detailed investigations for the regeneration conditions are still pending. Identification of substances accumulating on the catalyst should be possible via investigating the residues and their burn-off characteristics. As shown in Figure 5, the darkened catalyst due to coke deposits can be fully regenerated with the appropriate oxygen concentration and regeneration time. 


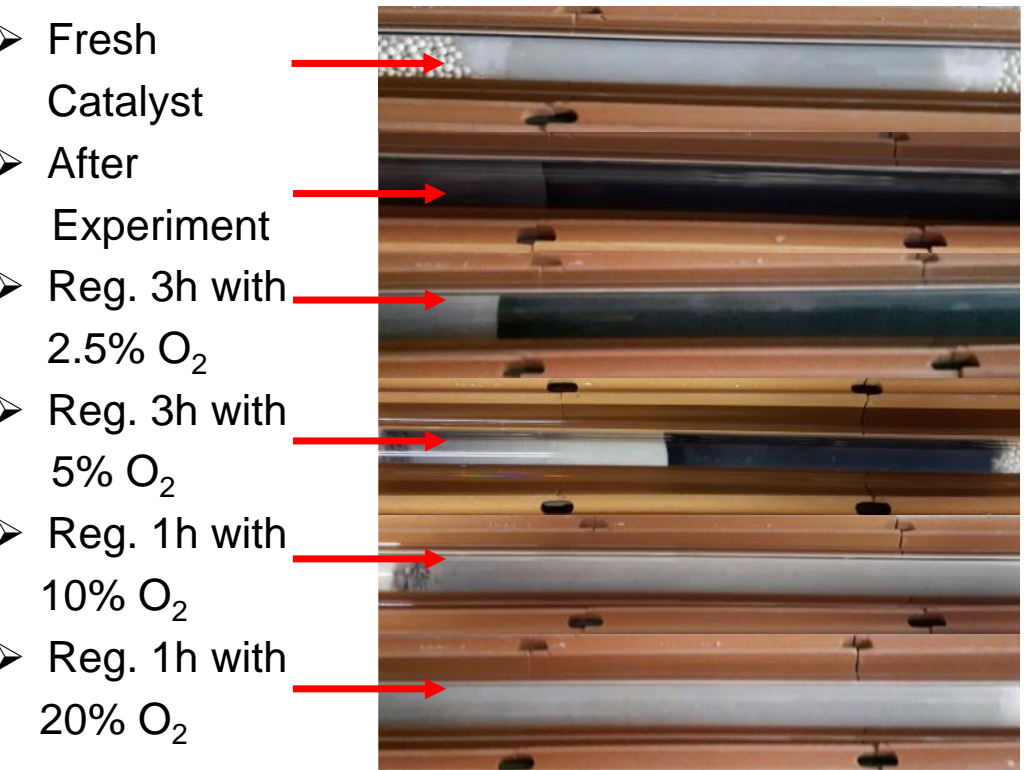

Figure 5: Dependency of the deactivated catalyst bed with varying regeneration time and oxygen concentration.

A regeneration model with its kinetic parameters is needed to optimize an overall process (Figure 6). Such processes consist of a production phase, with reaction and simultaneous deactivation, and regeneration phases, where no product is obtained. The resulting time, of both the deactivation and regeneration phase, gives the cyclic time for the process. A necessity is knowledge regarding the kinetics of deactivation and regeneration. Both detailed information benefits one to optimize each step and the overall process according to the desired performance parameter, by choosing optimal stoppage criteria. 


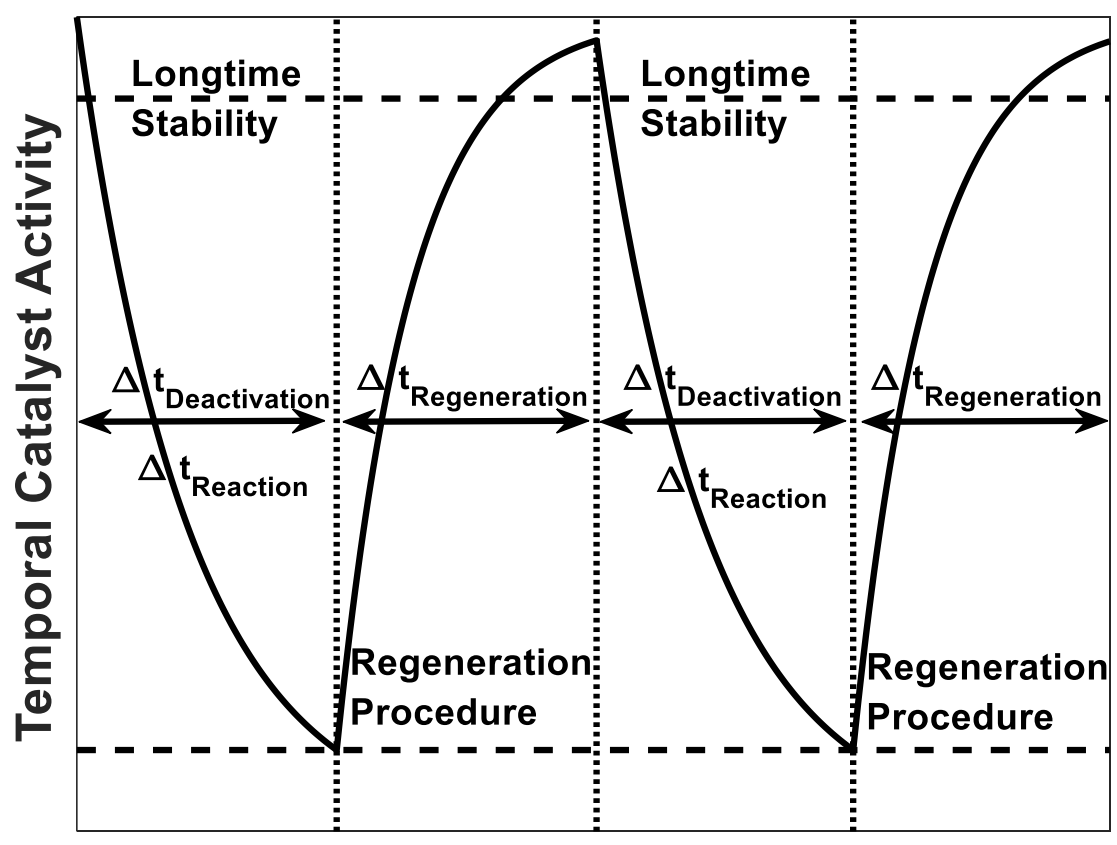

Time

Figure 6: Exemplified cyclic operation of a reactor setup, with distinct reaction and deactivation, subsequently followed by regeneration, with stoppage criteria as low and high activity, initializing the following process step.

A plot summarizing the results of all 120 runs performed is shown in Figure 7. Exploiting periodically the described reactivation the $\mathrm{Ni} /(\mathrm{Al}) \mathrm{MCM}-41(\mathrm{Si} / \mathrm{Al}=60)$ a similar activity could be maintained over the whole measurement range of conditions. The entity of all performed experiments can be separated into 4 sections. In the first section, named "Feed+Temp", the limits of the experimental setup and the catalyst were evaluated. In this timeframe, the regeneration strategy was optimized. Therefore, not all experiments are suitable for consideration. Even though for some experiments not all of the preliminary activity could be regained, as shown in Figure 5, a prolonged regeneration allowed for an increase to the initial activity.

In the second section, named "Temp", the longtime stability of the catalytic system was evaluated, while repeating similar experiments. A steady value for propene selectivity is observed. Even though the conversion showed a slight decrease, only from 700 to $1000 \mathrm{~h}$, thus, an active and productive catalytic system was observed. With the application of pre-treatment and prolonged regeneration condition, the catalytic activity could be restored. Additionally, it becomes clear from Figure 7, that the reaction temperature is a major factor for the propene synthesize in the complex reaction network and deactivation. At temperatures lower than $300^{\circ} \mathrm{C}$ almost no reactant is converted. Regarding the desired product propene, a lower feed concentration appears beneficial. 
This is due to decreased side reactions, of enhanced dimerization/oligomerization and interaction of the feed the main product, the butenes.

For the third section, the "Feed" concentration was varied from 2,5 to $25 \%$ of ethene for constant temperatures of 250,300 and $350^{\circ} \mathrm{C}$. The temperature has a significant influence on the performance of the catalyst. Only low conversion and almost no selectivity to propene are seen below $300^{\circ} \mathrm{C}$. For varying inlet concentration two counter behaviors are monitored. Higher inlet concentration of ethene increases side reactions, therefore the selectivity of propene decreases. At the same time, the conversion of ethene increases, because of these side reactions, which enhances the effect of lower propene selectivity.
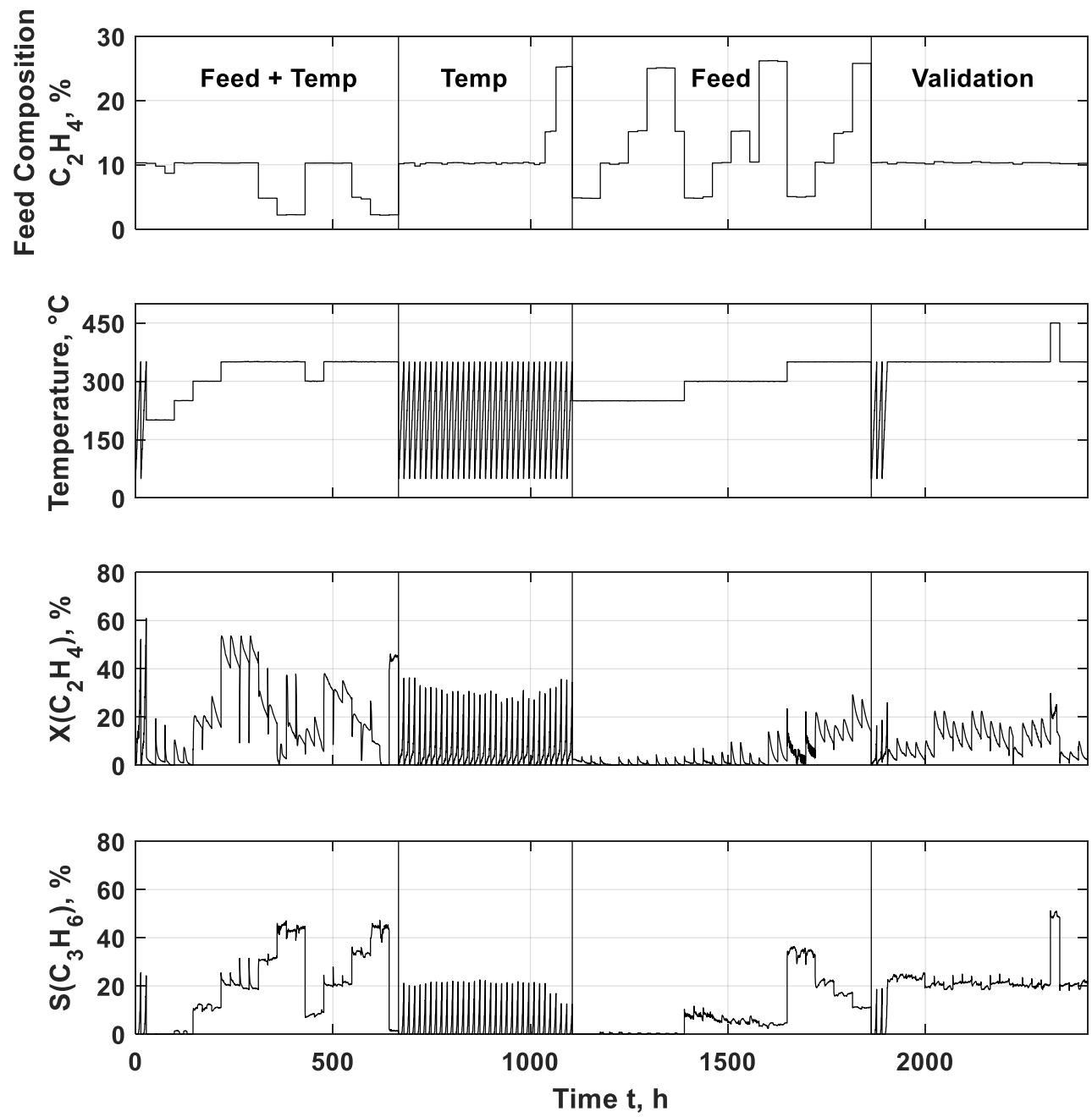

Figure 7: Summary of the conditions and corresponding performance criteria for the set of the Nex=120 sequentially carried out experiments using an identical sample of a (Ni/(Al)MCM-41) catalyst, concentration was varied from 2,5 to $25 \%$ of ethene, temperature was varied from 50 to $350^{\circ} \mathrm{C}$ and W/F was changed between 250 and $2000 \mathrm{~kg} \mathrm{Kat}^{\circ} \mathrm{s} / \mathrm{m}^{3}$. 
The last section of "Validation" presents a series of repetition experiments under constant conditions. A reproducible saw tooth profile is obtained for conversion, while selectivity is rather constant. These results show that the catalyst is still active after $2000 \mathrm{~h}$ of time on stream. Its morphology and properties are unchanged and give constant product distribution and quality.

\section{Conclusions}

The heterogeneously catalyzed synthesis of propene from ethene was studied for a Ni/(Al)MCM41 catalyst with a Si/Al ratio of 60 . A large set of experiments was performed, with varying feed concentration and catalyst weight-to-flow ratios, to identify and quantify the ongoing reactions. At first, an extended mechanistic cycle for the established reaction network suggested by Iwamoto [8], consisting of dimerization, isomerization and metathesis steps was applied. In an attempt to obtain a better representation of the experimental data, a modified reaction network was assumed in which catalytic cracking was considered, rather than a metathesis step for propene production. This allowed for an improved description and explanation of the observed product spectrum. It will be of interest to derive detailed mechanistically explanatory kinetic models, based on the catalytic cycles proposed.

Furthermore, deactivation behavior and its dependent kinetics were observed. Based on these observations a strategy for the catalyst regeneration was developed, implemented and successfully tested. This allowed operation of over $2000 \mathrm{~h}$ for a single catalyst bed with attractive stability.

In further work, a quantitative kinetic model for the applied catalytic system will be derived and evaluated. Further, parameters for the deactivation and regeneration have to analyzed and optimized to enhance the efficiency of the overall process ( $t_{\text {Dead }} / t_{\text {Reaction }}$ ), exemplified in Figure 6.

\section{AUTHOR INFORMATION}

Matthias Felischak:

Otto-von-Guericke Universität Magdeburg, Universitätsplatz 2, Postfach 4120, 39106 Magdeburg, Germany

\section{Author Contributions}

The manuscript was written through contributions of all authors. / All authors approved the final version of the manuscript. 


\section{Acknowledgements}

We would like to acknowledge and thank the DAAD (Germany) and CONACYT (Mexico) for their funding of the international exchange of knowledge. Further, we would especially like to thank Jutta Wilke for supporting the experimental realization and the colleagues at the OvGU for helpful discussions.

\section{Abbreviations}

ETP - Ethene-to-Propene; GC - gas chromatography; HTKR - High Temperature Kinetic Reactor; MCM - Mobile composition of matter; OCT - Olefin Conversion Process; SAPO - Small-pore molecular sieves; SBA - Santa Barbara Amorphous material; W/F - Weightto-Flow; ZSM - Zeolite Socony mobile

\section{References}

[1] A.V. Lavrenov, L.F. Saifulina, E.A. Buluchevskii, E.N. Bogdanets, Propylene production technology, Catal. Ind. 7 (2015) 175-187.

[2] S.B. Kogan, M. Herskowitz, Selective propane dehydrogenation to propylene on novel bimetallic catalysts, Catalysis Communications 2 (2001) 179-185.

[3] J. Mol, Industrial applications of olefin metathesis, Journal of Molecular Catalysis A: Chemical 213 (2004) 39-45.

[4] X. Zhu, S. Liu, Y. Song, L. Xu, Butene Catalytic Cracking to Propene and Ethene over Potassium Modified ZSM-5 Catalysts, Catal Lett 103 (2005) 201-210.

[5] X. Zhu, X. Li, S. Xie, S. Liu, G. Xu, W. Xin, S. Huang, L. Xu, Two New On-Purpose Processes Enhancing Propene Production: Catalytic Cracking of C4 Alkenes to Propene and Metathesis of Ethene and 2-Butene to Propene, Catal Surv Asia 13 (2009) 1-8.

[6] S. Huang, S. Liu, W. Xin, J. Bai, S. Xie, Q. Wang, L. Xu, Metathesis of ethene and 2-butene to propene on W/Al2O3-HY catalysts with different HY contents, Journal of Molecular Catalysis A: Chemical 226 (2005) 61-68.

[7] L. Alvarado Perea, T. Wolff, P. Veit, L. Hilfert, F.T. Edelmann, C. Hamel, A. SeidelMorgenstern, Alumino-mesostructured Ni catalysts for the direct conversion of ethene to propene, Journal of Catalysis 305 (2013) 154-168.

[8] M. Iwamoto, Conversion of Ethene to Propene on Nickel Ion-loaded Mesoporous Silica Prepared by the Template Ion Exchange Method, Catal Surv Asia 12 (2008) 28-37.

[9] F. Cavani, N. Ballarini, A. Cericola, Oxidative dehydrogenation of ethane and propane, Catalysis Today 127 (2007) 113-131.

[10] H.A. Wittcoff, B.G. Reuben, J.S. Plotkin, Industrial organic chemicals, third edition, 3rd ed., Wiley, Hoboken, N.J., 2013.

[11] J.S. Buchanan, J.G. Santiesteban, W.O. Haag, Mechanistic Considerations in Acid-Catalyzed Cracking of Olefins, Journal of Catalysis 158 (1996) 279-287. 
[12] A. Corma, F.V. Melo, L. Sauvanaud, Kinetic and decay cracking model for a MicroDowner unit, Applied Catalysis A: General 287 (2005) 34-46.

[13] B. Wang, Q. Gao, J. Gao, D. Ji, X. Wang, J. Suo, Synthesis, characterization and catalytic C4 alkene cracking properties of zeolite ZSM-23, Applied Catalysis A: General 274 (2004) $167-172$.

[14] X. Zhu, S. Liu, Y. Song, S. Xie, L. Xu, Catalytic cracking of 1-butene to propene and ethene on MCM-22 zeolite, Applied Catalysis A: General 290 (2005) 191-199.

[15] X. Zhu, S. Liu, Y. Song, L. Xu, Catalytic cracking of C4 alkenes to propene and ethene, Applied Catalysis A: General 288 (2005) 134-142.

[16] J. Lu, Z. Zhao, C. Xu, A. Duan, P. Zhang, CrHZSM-5 Zeolites - Highly Efficient Catalysts for Catalytic Cracking of Isobutane to Produce Light Olefins, Catal Lett 109 (2006) 65-70.

[17] M. Taoufik, E. Le Roux, J. Thivolle-Cazat, J.-M. Basset, Direct Transformation of Ethylene into Propylene Catalyzed by a Tungsten Hydride Supported on Alumina, Angew. Chem. Int. Ed. 46 (2007) 7202-7205.

[18] H. Oikawa, Y. Shibata, K. Inazu, Y. Iwase, K. Murai, S. Hyodo, G. Kobayashi, T. Baba, Highly selective conversion of ethene to propene over SAPO-34 as a solid acid catalyst, Applied Catalysis A: General 312 (2006) 181-185.

[19] B. Lin, Q. Zhang, Y. Wang, Catalytic Conversion of Ethylene to Propylene and Butenes over H-ZSM-5, Ind. Eng. Chem. Res. 48 (2009) 10788-10795.

[20] M. Iwamoto, One step formation of propene from ethene or ethanol through metathesis on nickel ion-loaded silica, Molecules (Basel, Switzerland) 16 (2011) 7844-7863.

[21] T. Lehmann, T. Wolff, V.M. Zahn, P. Veit, C. Hamel, A. Seidel-Morgenstern, Preparation of Ni-MCM-41 by equilibrium adsorption - Catalytic evaluation for the direct conversion of ethene to propene, Catalysis Communications 12 (2011) 368-374.

[22] T. Lehmann, T. Wolff, C. Hamel, P. Veit, B. Garke, A. Seidel-Morgenstern, Physicochemical characterization of Ni/MCM-41 synthesized by a template ion exchange approach, Microporous and Mesoporous Materials 151 (2012) 113-125.

[23] N.A.S. Amin, D.D. Anggoro, Characterization and Activity of Cr, Cu and Ga Modified ZSM5 for Direct Conversion of Methane to Liquid Hydrocarbons, Journal of Natural Gas Chemistry 12 (2003) 123-134.

[24] R.D. Andrei, M.I. Popa, C. Cammarano, V. Hulea, Nickel and molybdenum containing mesoporous catalysts for ethylene oligomerization and metathesis, New J. Chem. 40 (2016) 4146-4152.

[25] W. Dai, X. Sun, B. Tang, G. Wu, L. Li, N. Guan, M. Hunger, Verifying the mechanism of the ethene-to-propene conversion on zeolite H-SSZ-13, Journal of Catalysis 314 (2014) 1020.

[26] X. Ding, S. Geng, C. Li, C. Yang, G. Wang, Effect of acid density of HZSM-5 on the oligomerization of ethylene in FCC dry gas, Journal of Natural Gas Chemistry 18 (2009) $156-160$.

[27] S. Liu, S. Huang, W. Xin, J. Bai, S. Xie, L. Xu, Metathesis of ethylene and butylene-2 to propylene with Mo on H $\beta-A 12 \mathrm{O} 3$ catalysts, Catalysis Today 93-95 (2004) 471-476.

[28] A.S. Frey, O. Hinrichsen, Comparison of differently synthesized Ni(Al)MCM-48 catalysts in the ethene to propene reaction, Microporous and Mesoporous Materials 164 (2012) 164171.

[29] A.S. Henkel, Direkte Umsetzung von Ethen zu Propen mit Nickelkatalysatoren. Dissertation, München, 2013. 
[30] L. Li, R.D. Palcheva, K.-J. Jens, Conversion of Ethene to Propene by a Dual Function NiSO4/Re2O7/ $\gamma$-A12O3 Catalyst, Top Catal 56 (2013) 783-788.

[31] A.V. Lavrenov, T.R. Karpova, E.A. Buluchevskii, E.N. Bogdanets, Heterogeneous oligomerization of light alkenes, Catal. Ind. 8 (2016) 316-327.

[32] L. Noreña-Franco, I. Hernandez-Perez, J. Aguilar-Pliego, A. Maubert-Franco, Selective hydroxylation of phenol employing $\mathrm{Cu}-\mathrm{MCM}-41$ catalysts, Catalysis Today 75 (2002) 189195.

[33] L. Alvarado Perea, Direct conversion of ethene to propene on Ni-alumino-mesostructured catalysts: synthesis, characterization and catalytic testing, Magdeburg, 2014.

[34] G. Kiedorf, D.M. Hoang, A. Müller, A. Jörke, J. Markert, H. Arellano-Garcia, A. SeidelMorgenstern, C. Hamel, Kinetics of 1-dodecene hydroformylation in a thermomorphic solvent system using a rhodium-biphephos catalyst, Chemical Engineering Science 115 (2014) 31-48.

[35] L. Alvarado Perea, T. Wolff, C. Hamel, A. Seidel-Morgenstern, Experimental study of the deactivation of Ni/AlMCM-41 catalyst in the direct conversion of ethene to propene, Applied Catalysis A: General 533 (2017) 121-131.

[36] K. Amakawa, S. Wrabetz, J. Kröhnert, G. Tzolova-Müller, R. Schlögl, A. Trunschke, In situ generation of active sites in olefin metathesis, Journal of the American Chemical Society 134 (2012) 11462-11473.

[37] M. Argyle, C. Bartholomew, Heterogeneous Catalyst Deactivation and Regeneration, Catalysts 5 (2015) 145-269.

[38] J.R. Sohn, W.C. Park, Ethylene dimerization catalyst of nickel sulfate supported on silicaalumina, Korean J. Chem. Eng. 17 (2000) 727-730.

[39] J.R. Sohn, W.C. Park, D.C. Shin, Characterization of nickel sulfate supported on SiO2 for ethylene dimerization and promoting effect of Al2O3 on catalytic activity, Journal of Molecular Catalysis A: Chemical 256 (2006) 156-163.

[40] R.D. Broene, M. Brookhart, W.M. Lamanna, A.F. Volpe, Cobalt-catalyzed dimerization of alpha-olefins to give linear alpha-olefin products, Journal of the American Chemical Society 127 (2005) 17194-17195.

[41] M. Hartmann, A. Pöppl, L. Kevan, Ethylene Dimerization and Butene Isomerization in Nickel-Containing MCM-41 and, J. Phys. Chem. C 100 (1996) 9906-9910.

[42] L. Bonneviot, D. Olivier, M. Che, Dimerization of Olefins with nickel-surface complexes in X-type zeolite or on silica, Journal of Molecular Catalysis A: Chemical 21 (1983) 415-430.

[43] J. Rabeah, J. Radnik, V. Briois, D. Maschmeyer, G. Stochniol, S. Peitz, H. Reeker, C. La Fontaine, A. Brückner, Tracing Active Sites in Supported Ni Catalysts during Butene Oligomerization by Operando Spectroscopy under Pressure, ACS Catal. 6 (2016) 82248228.

[44] R.D. Andrei, M.I. Popa, F. Fajula, V. Hulea, Heterogeneous oligomerization of ethylene over highly active and stable Ni-A1SBA-15 mesoporous catalysts, Journal of Catalysis 323 (2015) 76-84.

[45] M.J. Baird, J.H. Lunsford, Catalytic sites for the isomerization of 1-butene over Magnesium oxide, Journal of Catalysis 26 (1972) 440-450.

[46] P. Dejavifve, Reaction pathways for the conversion of methanol and olefins on H-ZSM-5 zeolite, Journal of Catalysis 63 (1980) 331-345.

[47] O. Bortnovsky, P. Sazama, B. Wichterlova, Cracking of pentenes to C2-C4 light olefins over zeolites and zeotypes, Applied Catalysis A: General 287 (2005) 203-213. 
[48] C.-J. Chen, S. Rangarajan, I.M. Hill, A. Bhan, Kinetics and Thermochemistry of C 4 -C 6 Olefin Cracking on H-ZSM-5, ACS Catal. 4 (2014) 2319-2327.

[49] A. Corma, A.V. Orchillés, Current views on the mechanism of catalytic cracking, Microporous and Mesoporous Materials 35-36 (2000) 21-30.

\section{Supporting Information}
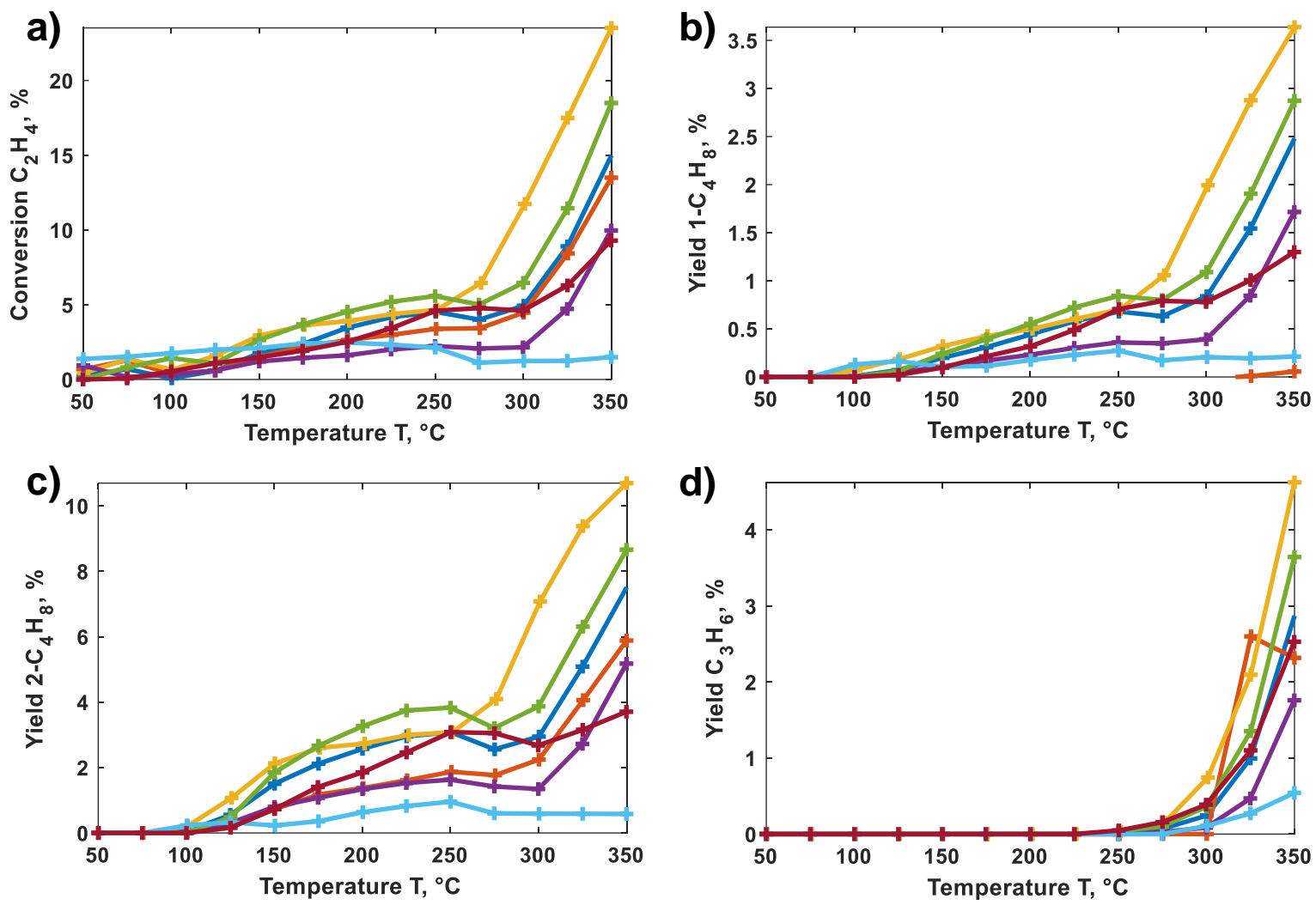

$$
\begin{aligned}
& \longrightarrow x\left(C_{2} H_{4}^{0}\right)=10 \mathrm{Vol}-\% ; W / F=500 \mathrm{~kg}_{\mathrm{Kat}} \cdot \mathrm{s} / \mathrm{m}^{3} \\
& \longrightarrow x\left(\mathrm{C}_{2} \mathrm{H}_{4}^{0}\right)=10 \mathrm{Vol}-\% ; W / \mathrm{F}=750 \mathrm{~kg}_{\mathrm{Kat}} \cdot \mathrm{s} / \mathrm{m}^{3} \\
& \longrightarrow x\left(C_{2} H_{4}^{0}\right)=10 \mathrm{Vol}-\% ; W / F=500 \mathrm{~kg}_{\mathrm{Kat}} \cdot \mathrm{s} / \mathrm{m}^{3} \\
& -\mathrm{x}\left(\mathrm{C}_{2} \mathrm{H}_{4}^{0}\right)=2.5 \mathrm{Vol}-\% ; \mathrm{W} / \mathrm{F}=500 \mathrm{~kg}_{\mathrm{Kat}} \cdot \mathrm{s} / \mathrm{m}^{3} \\
& -x\left(C_{2} H_{4}^{0}\right)=10 \mathrm{Vol}-\% ; W / F=500 \mathrm{~kg}_{\mathrm{Kat}} \cdot \mathrm{s} / \mathrm{m}^{3} \mathrm{pre} \longrightarrow x\left(\mathrm{C}_{2} \mathrm{H}_{4}^{0}\right)=5 \mathrm{Vol}-\% ; W / F=500 \mathrm{~kg} \mathrm{Kat} \cdot \mathrm{s} / \mathrm{m}^{3} \\
& \longrightarrow x\left(C_{2} H_{4}^{0}\right)=10 \mathrm{Vol}-\% ; W / F=250 \mathrm{~kg}_{\mathrm{Kat}} \cdot \mathrm{s} / \mathrm{m}^{3}
\end{aligned}
$$

$S$ 1: Conversion of ethene (a), yield of 1-butene (b), 2-butene (c) and propene (d) over temperature for Ni/(Al)MCM-41 $(S i / A l=60)$. 